\title{
Advancement of sorption-based heat transformation by a metal coating of highly-stable, hydrophilic aluminium fumarate MOF $\uparrow$
}

\begin{abstract}
Felix Jeremias, ${ }^{\text {ab }}$ Dominik Fröhlich, ${ }^{\text {ab }}$ Christoph Janiak ${ }^{\star a}$ and Stefan K. Henninger ${ }^{\star b}$
The distinctive water sorption properties of microporous aluminium fumarate (s-shaped isotherm, narrow hysteresis, loading $>0.3 \mathrm{~g} \mathrm{~g}^{-1}$ at a relative pressure as low as $p / p_{0}=0.3$ under realistic working conditions) permit a large advancement of MOF-based sorption heat transformation processes, especially as we demonstrate that the favourable sorption properties are accompanied by an unprecedented cyclic hydrothermal stability. With regard to the application of heat transformation, where unhindered heat and mass transfer are crucial for fast ad-/desorption cycles and a high power density, the question of proper shaping was also addressed. A $300 \mu \mathrm{m}$ thick, polycrystalline, thermally well coupled and highly accessible coating of microporous aluminium fumarate was deposited on a metal substrate via the thermal gradient approach, and found to be stable for the first $4500 \mathrm{ad}$-/desorption cycles with water vapour.
\end{abstract}

www.rsc.org/advances

\section{Introduction}

Metal-organic frameworks (MOFs) receive continuous attention due to their unsurpassed porosity and chemical variability, which both originate from the inherent, molecular clusterlinker concept. ${ }^{1}$ Substantial progress can be expected from their introduction into the fields of gas storage, ${ }^{2,3}$ gas $^{4}$ and liquid ${ }^{5}$ separation processes, drug delivery, ${ }^{6}$ heterogeneous catalysis ${ }^{7}$ and other applications, ${ }^{8}$ but especially for sorption-based heat transformation purposes.

Thermally driven adsorption chillers (TDCs) or adsorption heat pumps (AHPs) pose an alternative to traditional air conditioners, heat pumps or condensing boilers operating on electricity or fossil fuels. Driven by solar or waste heat, TDCs/ AHPs can help to minimize primary energy consumption. They are based on the evaporation of coolants, preferably water, and consecutive adsorption at a microporous material under specific conditions.

This technology has gained more and more interest during the last years, because it allows waste heat, which would otherwise be simply released to the environment, to be used for

anstitut für Anorganische Chemie und Strukturchemie, Universität Düsseldorf, 40204 Düsseldorf, Germany. E-mail: janiak@uni-duesseldorf.de

${ }^{b}$ Department of Thermally Active Materials and Solar Cooling, Fraunhofer Institute for Solar Energy Systems (ISE), Heidenhofstr. 2, 79110 Freiburg, Germany

$\dagger$ Electronic supplementary information (ESI) available: $\mathrm{N}_{2}$ adsorption isotherm, PXRD (literature, bulk $\mu \mathrm{p}-\mathrm{AF}$ and coated sheets), heat capacity and FT-IR spectrum of bulk $\mu \mathrm{p}-\mathrm{AF}$, PXRD of the top and bottom layer of the coating, desorption isobar of sheet 2, individual diffractograms for the in situ ad-/desorption study, and crystal structures of related MIL-53. See DOI: 10.1039/c4ra03794d cooling applications, or stored, e.g., for heating in winter. Additionally, the process can be operated in heat-pump mode: as additional thermal energy from the environment can be used for heating, less fuel is required. ${ }^{9-11}$ It is clear that the performance, efficiency and range of use of a sorption-based heat pump, or chiller, drastically depend on the performance of the applied sorption material. MOFs are of high interest for the use as adsorbents, as they can surpass classical materials like silica gels or zeolites in terms of fluid uptake capacity and also offer the potential for tuning the microporosity and hydrophilicity through their variable building blocks depending on the specific heat transformation application. MOFs are being increasingly investigated for this purpose because of their high porosities, tunable hydrophilicities, and inherent, narrow pore size distributions which result in a sharp loading step. However, low hydrophilicity, insufficient hydrothermal stability and a pricey production still impede their commercial success in this and related fields. ${ }^{9,12-18}$

While the chemical properties of a MOF material can be tailored to meet the specifications of a particular task, ${ }^{19}$ harsh environmental conditions and especially the presence of water vapour often result in irreversible structural transformations and rapid loss of porosity especially in well-established and examined materials: copper trimesate HKUST-1 (although it is synthesized in aqueous solution), zinc terephthalate MOF-5, and even zirconium aminoterephthalate $\mathrm{H}_{2} \mathrm{~N}-\mathrm{UiO}-66$ show framework disintegration under humid working conditions. ${ }^{15,20,21}$ The decomposition process has been found to commence at the metal-linker coordination bond in most cases. ${ }^{21}$ The collection of better water-stable MOFs includes many zeolitic imidazolate frameworks (ZIFs) ${ }^{22}$ and a few other 
azolate-derived compounds, ${ }^{16,23}$ MOFs based on Cr(III) (such as MIL-101), ${ }^{14}$ or use $4^{\text {th }}$ group metal clusters, ${ }^{15,24}$ some MOFs that employ phosphonates as linkers, ${ }^{25}$ and so on. However, hydrothermal stability is often achieved by hydrophobicity, which can easily be deduced from the comparatively late rise of the water sorption isotherm. This is the case, e.g., for many ZIFs, metal azolate-carboxylate MOFs, ${ }^{26}$ and to some extent also MIL-101.

Suitable equilibrium sorption characteristics are a necessary requirement for any MOF application, but when it comes to fast, cyclic adsorption processes, unhindered heat and mass transfer have to be ensured as well. Hence, the MOF cannot be used as a powder, but must be fabricated into a device. While elaborate procedures are available for the production of custom-made, yet low-capacity $\mu \mathrm{m}$-films, e.g., by means of direct or seeded growth, ${ }^{27}$ electrochemical synthesis, ${ }^{28}$ microwave-induced ${ }^{29}$ or self-assembled monolayer (SAM-) assisted deposition, ${ }^{30}$ results are scarce when it comes to high-capacity, sturdy, firmly adhering films or membranes which are at the same time highly accessible and thermally well coupled to the substrate. Such films are necessary for high-turnover applications in the field of gas sorption, catalysis etc., where substantial amounts of heat have to be delivered or dissipated, with sorption-based heat transformation being an especially challenging task for the material because of the recurring ad- and desorption cycles (Fig. 1).

Microporous aluminium fumarate (abbreviated as $\mu \mathrm{p}-\mathrm{AF}$ in this publication) keeps appearing in the patent literature since $2007,,^{31,32}$ and it distinguishes from other MOFs especially by the fact that it can be easily prepared from inexpensive reagents via a water-based precipitation approach. This also means that at least some water stability can be anticipated. Gas separation, $\mathrm{H}_{2}$ or methane storage, and storage and release of liquid agents have been named as possible applications for $\mu \mathrm{p}-\mathrm{AF}$, for which it may be marketed by BASF as Basolite ${ }^{\mathrm{TM}} \mathrm{A} 520 .^{31,33}$ These facts all point out that $\mu \mathrm{p}-\mathrm{AF}$ can become one of the commercially

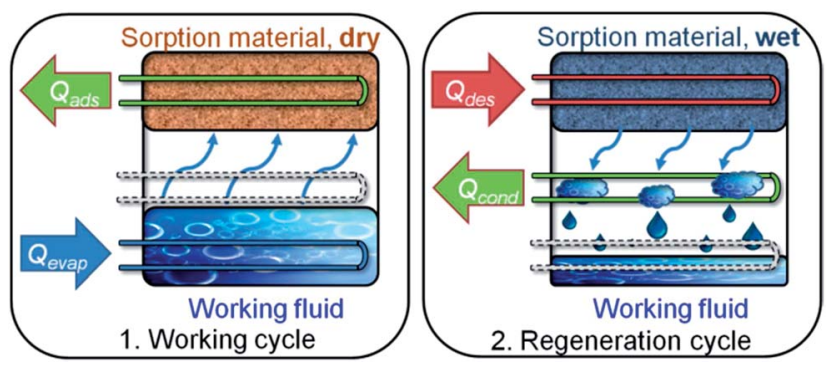

Fig. 1 Working principle of a sorption heat pump/chiller. (1) Working cycle: a working fluid (typically $\mathrm{H}_{2} \mathrm{O}$ due to the high evaporation enthalpy of $44 \mathrm{~kJ} \mathrm{~mol}^{-1}$ ) is evaporated at low pressure by application of evaporation heat $Q_{\text {evap }}$, and adsorbed at a microporous material, releasing adsorption heat $Q_{\text {ads. }}$ (2) Regeneration cycle: when the adsorbent is saturated, driving heat $Q_{\text {des }}$ is applied for desorption of the working fluid. The vapour then condenses at a cooler, and condensation heat $Q_{\text {des }}$ is released. Energy is now stored until reinitiation of the working cycle. Note: low temperature $(T)$ heat is depicted in blue, medium $T$ heat in green and high $T$ heat in red. Copyright by the Royal Society of Chemistry, reproduced by permission of the authors of ref. 13 .

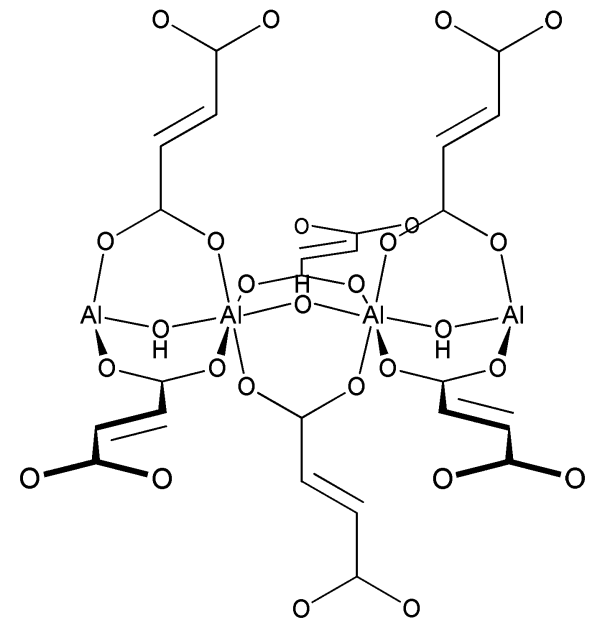

Scheme 1 Probable building block in $\mu \mathrm{p}-\mathrm{AF}$ based on the analogy to MIL-53.

most important MOFs, but, curiously enough, publications in scientific journals remain scarce. ${ }^{33,34}$

Structurally, $\mu \mathrm{p}-\mathrm{AF}$ resembles MIL-53, as it also consists of infinite $\mathrm{Al}-\mathrm{OH}-\mathrm{Al}$ chains connected by fumarate linkers (Scheme 1). ${ }^{35}$ From this comparison, a 3D structure consisting of $\left[\mathrm{Al}(\mathrm{OH})\left(\mathrm{O}_{2} \mathrm{C}-\mathrm{CH}=\mathrm{CH}-\mathrm{CO}_{2}\right)\right]$ with rhombohedral channels is probably formed (see Fig. S8 in ESI $\dagger$ ). ${ }^{31}$

Here, a MOF-based material with promising properties (capacity, sorption behaviour, multi-cycle stability), and also a method for the production of a coating on a metallic substrate are presented. In this contribution, we demonstrate the unprecedented water-stability and hydrophilicity of $\mu \mathrm{p}-\mathrm{AF}$ and fabricate this MOF into a thermally well coupled coating on aluminium metal sheets, e.g., for use on heat exchangers in sorption-based heat transformation applications.

\section{Experimental}

\subsection{Synthesis of bulk- $\mu$ p-AF}

Although a convenient water-based precipitation approach for the synthesis of microporous aluminium fumarate, $\mu \mathrm{p}-\mathrm{AF}$ is known, a different patent procedure using dimethyl formamide as the solvent was chosen because of the alleged better reaction control, and adaptability towards the fabrication of MOF coatings. ${ }^{31}$ In a $1000 \mathrm{~mL}$ round bottom flask, $26.9 \mathrm{~g}(108 \mathrm{mmol})$ of aluminium chloride hexahydrate (p.a., Merck) and $15.4 \mathrm{~g}$ (133 mmol) of fumaric acid ( $\geq 99.5 \%$, Carl Roth) were dissolved in $550 \mathrm{~mL}$ of freshly distilled dimethyl formamide ( $\geq 99.5 \%$, Carl Roth). The turbid, yellowish mixture was stirred at $130{ }^{\circ} \mathrm{C}$ for 4 days. After cooling, the snow-white precipitate was filtered off and stirred twice in redist. acetone ( $1 \mathrm{~h}$ and $24 \mathrm{~h}, 200 \mathrm{~mL}$ each), and twice in redist. ethanol ( $1 \mathrm{~h}$ and $24 \mathrm{~h}, 200 \mathrm{~mL}$ each). The solid was then dried in air at $80{ }^{\circ} \mathrm{C}$. Yield: $15.4 \mathrm{~g}(90 \%$ based on Al). IR, neat (ATR), 3385, 1593, 1471, 1419, 1212, 1152, 1005, 985, 804, 713, 694, 646, $483 \mathrm{~cm}^{-1}$ (see Fig. $\mathrm{S} 4 \dagger$ ). $\mathrm{C}_{4} \mathrm{H}_{3} \mathrm{O}_{5} \mathrm{Al}$ (158.04) calc. C 30.40, H 1.91\%; found C 30.91, H 2.82. 


\subsection{Thermal gradient coating}

2.2.1 Aluminium substrate sheet preparation. Aluminium sheets $\left(50 \times 50 \times 1.0 \mathrm{~mm}^{3}\right)$ were sanded on both sides, etched in sodium hydroxide solution $\left(140 \mathrm{~g} \mathrm{~L}^{-1}, 65{ }^{\circ} \mathrm{C}, 90 \mathrm{~s}\right)$, deoxidized in diluted nitric acid (13\%, RT, $30 \mathrm{~s})$ and dried in air at 60 ${ }^{\circ} \mathrm{C}$. Directly prior to use, both sheets were clamped to a custommade aluminium heating cartridge equipped with a surface thermocouple, ${ }^{\mathbf{1 7}}$ and the whole assembly was deoxidized again with diluted $\mathrm{HNO}_{3}$ and carefully rinsed using water and dimethyl formamide. The accessible surface of each sheet was $13 \mathrm{~cm}^{2}$.

2.2.2 Coating synthesis. For a typical synthesis, a solution of $\mathrm{Al}\left(\mathrm{NO}_{3}\right)_{3} \cdot 9 \mathrm{H}_{2} \mathrm{O}$ (Merck, $20.08 \mathrm{~g}$ ) and fumaric acid (Carl Roth, $10.68 \mathrm{~g}$ ) in freshly distilled dimethyl formamide (Carl Roth, 200 $\mathrm{mL}$ ) was filled into a stainless steel beaker $(65 \mathrm{~mm}$ inner diameter) thermostated to $30{ }^{\circ} \mathrm{C}$. Using a custom-made aluminium heating apparatus as described in the literature, ${ }^{17}$ the Al substrate sheet was immersed into the solution and heated to a temperature of $145{ }^{\circ} \mathrm{C}$ for $3 \mathrm{~h}$. After cooling, the $\mathrm{Al}$ sheet was carefully removed, rinsed with and soaked overnight in DMF, then rinsed with and soaked overnight in ethanol, finally dried in air at $50{ }^{\circ} \mathrm{C}$. Coating yield was $147 \mathrm{mg}(11.3 \mathrm{mg}$ $\mathrm{cm}^{-2}$ ) for sheet $1,172 \mathrm{mg}\left(13.2 \mathrm{mg} \mathrm{cm}^{-2}\right)$ for sheet 2 .

2.2.3 Protective coating. At RT, $10.0 \mathrm{~mL}$ of Silikophen ${ }^{\circledR}$ P 50/300 (Evonik Industries) were dissolved in $30.0 \mathrm{~mL}$ of xylene $(o / m / p$, technical grade). Sheet 2 was dipped into the solution, removed after $20 \mathrm{~s}$, and dried over night at RT in air. The sample was then tempered according to the following program (ramp time/temperature/hold time): $60 \mathrm{~min} / 50{ }^{\circ} \mathrm{C} / 120 \mathrm{~min} ; 180 \mathrm{~min} /$ $105{ }^{\circ} \mathrm{C} / 120 \mathrm{~min} ; 120 \mathrm{~min} / 250{ }^{\circ} \mathrm{C} / 180 \mathrm{~min} ; 300 \mathrm{~min} / \mathrm{RT}$. Total mass increase was $33.1 \mathrm{mg}$, which equals a varnish content in the $\mu \mathrm{p}-\mathrm{AF}$ layer of $19 \%$ assuming that the silicone resin accumulates mainly at the rough $\mu \mathrm{p}-\mathrm{AF}$ surface, not at the backside.

\subsection{Analytics: procedure and instrumentation}

$\mathrm{N}_{2}$ adsorption isotherms were obtained on a Quantachrome ${ }^{\circledR}$ Nova @ $77 \mathrm{~K}$, after vac. degassing $\left(120^{\circ} \mathrm{C} / 24 \mathrm{~h}\right) . \mathrm{H}_{2} \mathrm{O}$ adsorption isotherms: obtained on a Quantachrome ${ }^{\circledR}$ Hydrosorb, after vac. degassing $\left(120{ }^{\circ} \mathrm{C} / 24 \mathrm{~h}\right) \cdot \mathrm{H}_{2} \mathrm{O}$ adsorption isobars and powder cycle stability were examined in a Setaram ${ }^{\mathrm{TM}}$ TGA-DSC-111. A humidified argon gas flow $\left(40{ }^{\circ} \mathrm{C}, 76.3 \%\right.$ relative humidity) was generated by a Setaram ${ }^{\mathrm{TM}}$ WetSys humidity controller and passed through the sample chamber, while the temperature of the sample chamber itself was varied. For multi-cycle ad-/ desorption experiments, the temperature of the sample chamber was varied between $40{ }^{\circ} \mathrm{C}$ and $140{ }^{\circ} \mathrm{C}$ with a cycle time of $5 \mathrm{~h}$. X-ray diffractograms were acquired on a Bruker D8 Advance with DaVinci ${ }^{\mathrm{TM}}$, using a $\mathrm{Cu}$ anode tube at $40 \mathrm{kV} / 40 \mathrm{~mA}$, with a Ni filter and constant sample illumination spot size (broadness: $12 \mathrm{~mm}$ ); step size $0.02^{\circ}, 1.0 \mathrm{~s}$ per step, Cu-K $\alpha$ radiation. A rotating sample holder was used for powders. A MRI humidity chamber was used for controlled humidity experiments (Fig. 2d), where a humidified $\mathrm{N}_{2}$ gas flow was passed over the sample at atmospheric pressure. Before each scan, the sample was allowed to equilibrate for $90 \mathrm{~min}$. A Newport stage with three axes was used for coated sheets. IR
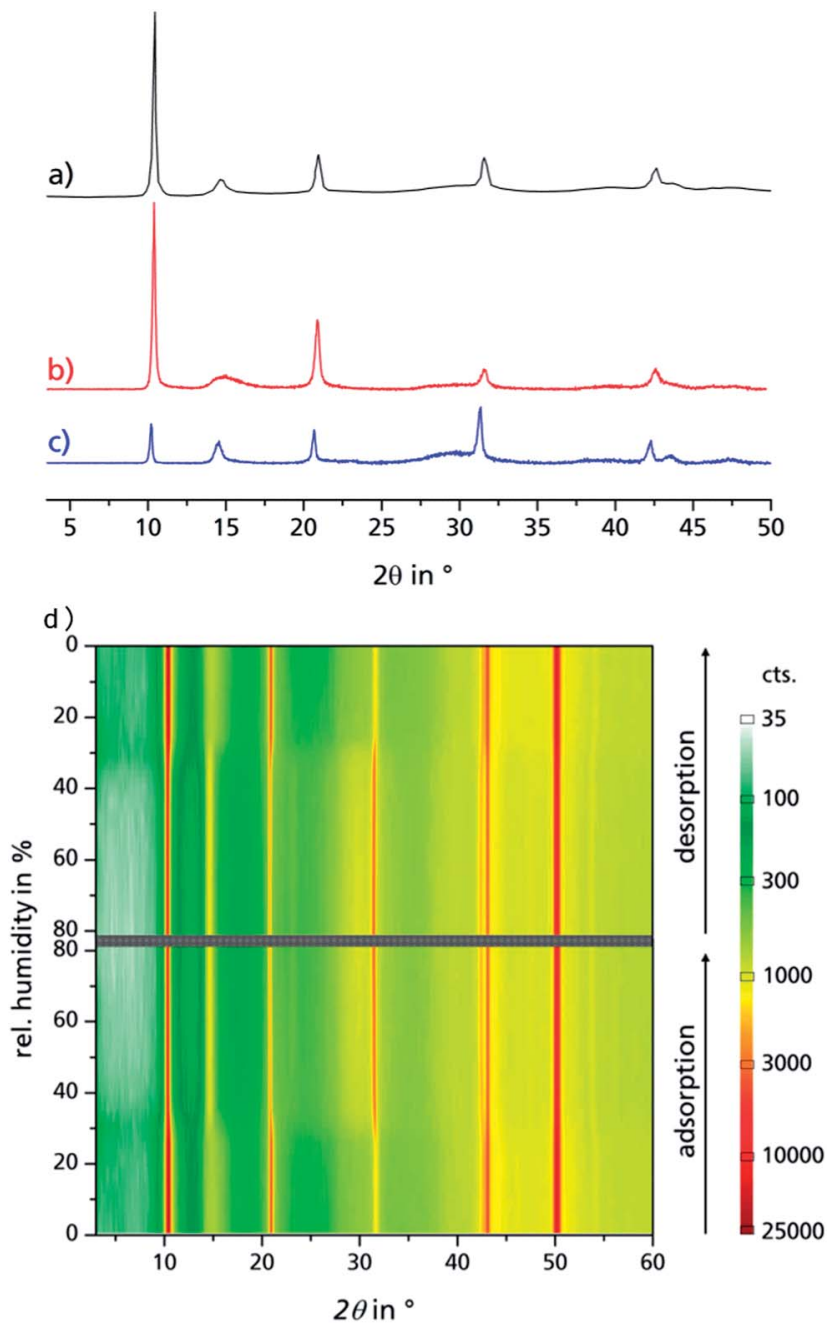

Fig. 2 PXRD of bulk $\mu p-A F$ as extracted from patent literature (a), dried $\mu \mathrm{p}-\mathrm{AF}$ (stored at $120^{\circ} \mathrm{C}$ under vacuum for $24 \mathrm{~h}(\mathrm{~b})$ ) and hydrated $\mu \mathrm{p}-\mathrm{AF}$ (stored under 100\% water vapour atmosphere overnight, (c)). (d) Reversible structural transition observed by in situ PXRD in a humidity chamber at $313 \mathrm{~K}$. See Fig. S5 in the ESI $\uparrow$ for the individual diffractograms.

spectra were obtained on a PerkinElmer ${ }^{\mathrm{TM}}$ SpectrumTwo FTIR equipped with a diamond ATR unit. Multi-cycle stability tests of coated samples: in order to investigate the adsorption/desorption cycle stability of $\mu$ p-AF over 1500 and another 3000 adsorption/desorption cycles, multi-cycle experiments were conducted in a special apparatus under pure water vapour atmosphere $(1300 \mathrm{~Pa})$, where the samples were clamped to a heating/cooling plate, with the temperature alternating between $125{ }^{\circ} \mathrm{C}$ and $20{ }^{\circ} \mathrm{C}$ for 90 seconds each. Hence, relative vapour pressure values of $p / p_{0}=0.006$ or, respectively, $p / p_{0}=0.55$, are generated and the main loading lift of $\mu \mathrm{p}-\mathrm{AF}$ is covered. Microscopic images were obtained on a Keyence ${ }^{\circledR}$ VHX reflected-light microscope. Scanning electron microscope images were obtained on a FEITM QUANTA 400 MK-II $(25 \mathrm{kV}$, ETdetector). Heat capacity of bulk aluminium fumarate was determined using a SETARAM ${ }^{\mathrm{TM}}$ SenSys evo DSC calorimeter. Heat conductivity and contact resistance were obtained on a 
NETZSCH LFA 457 laser flash analysis apparatus under vacuum. For the investigation of bulk aluminium fumarate, a pellet $(\varnothing=$ $12.7 \mathrm{~mm}$, forming pressure $=13 \mathrm{kN}$ ) was prepared. For investigation of the coating, a $10 \times 10 \mathrm{~mm}^{2}$ cut was used. Samples were coated with graphite on both sides and dehumidified at $120{ }^{\circ} \mathrm{C}$ prior to measurement. A Cowan 2-layer approach with regard to heat loss and pulse correction was applied. Heat capacity and thermal conductivity of the Al substrate were obtained from the Netzsch database, the heat capacity of the coating was calculated from the regression function given in the ESI. $\dagger$ For each temperature step, three values were taken, the given values are calculated as the arithmetic average. The calculation of the thermal conductivity was performed using the Netzsch software algorithm, which is based on the work by Hartmann et al. ${ }^{36}$

\section{Results and discussion}

\subsection{Bulk $\mu$ P-AF}

Aluminium chloride hexahydrate reacts with fumaric acid in dimethyl formamide (DMF) at $130{ }^{\circ} \mathrm{C}$ under formation of aluminium fumarate, $\left[\mathrm{Al}(\mathrm{OH})\left(\mathrm{O}_{2} \mathrm{C}-\mathrm{CH}=\mathrm{CH}-\mathrm{CO}_{2}\right)\right]$ in high yield. The product was verified by positively matching the powder X-ray diffractograms of both dried and rehydrated $\mu \mathrm{p} A \mathrm{~F}$ with the pattern given for genuine Basolite ${ }^{\mathrm{TM}}$ A520 in the literature (Fig. 2a-c). ${ }^{31}$

3.1.1 Pore analysis and $\mathrm{H}_{2} \mathrm{O}$ adsorption behaviour. $\mathrm{N}_{2}$ adsorption analysis yielded a BET surface of $S_{\mathrm{BET}}=1021 \mathrm{~m}^{2} \mathrm{~g}^{-1}$, and a micropore volume of $V_{\text {pore }}=0.48 \mathrm{~cm}^{3} \mathrm{~g}^{-1}$ (literature: $^{33}$ $S_{\text {Langmuir }}=1000-1200 \mathrm{~m}^{2} \mathrm{~g}^{-1}$, see ESI $\dagger$ for details).

Water adsorption isotherms were acquired in a temperature range between $298 \mathrm{~K}$ and $333 \mathrm{~K}$, leading to a maximum water vapour uptake of approx. $0.45 \mathrm{~g} \mathrm{~g}^{-1}$. The isotherms show a very favorable s-shape, with a steep increase in a narrow pressure range $\left(p / p_{0}=0.2-0.3\right)$ (Fig. 3 ). The desorption hysteresis is small compared to other, comparably hydrophilic MOFs like iron or aluminium trimesate, MIL-100 $(\mathrm{Fe}, \mathrm{Al})^{13}$ or zirconium

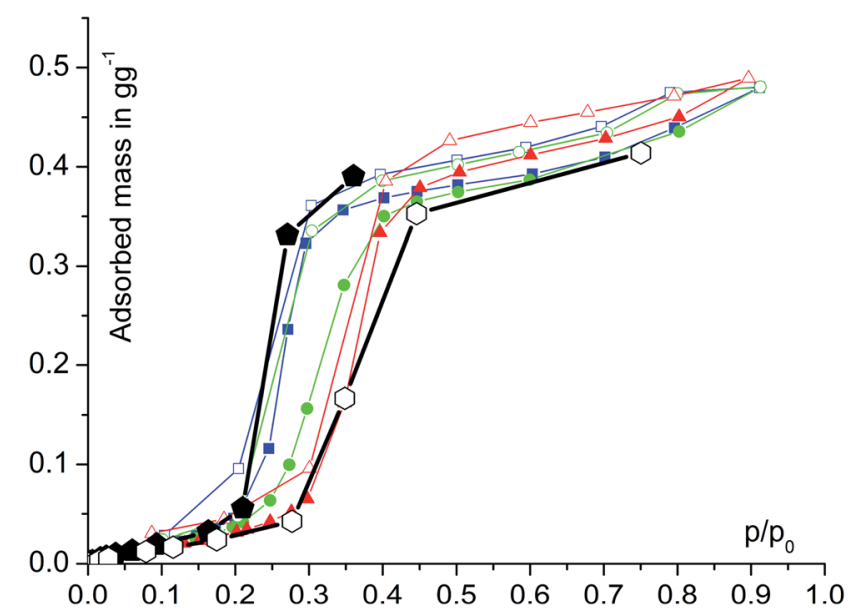

Fig. 3 Water sorption isotherms of bulk $\mu \mathrm{p}-\mathrm{AF}$, acquired at $25^{\circ} \mathrm{C}$ water $p_{0}=3.17 \mathrm{kPa},(\square), 40{ }^{\circ} \mathrm{C}\left(p_{0}=7.39 \mathrm{kPa},(0)\right.$ and $60{ }^{\circ} \mathrm{C} p_{0}=19.95$ $\mathrm{kPa},(\mathbf{\Delta})$, and isobars at $1.2 \mathrm{kPa}(\bullet)$ and $5.6 \mathrm{kPa}(0)$. Adsorption is depicted with filled, desorption with empty symbols. aminoterephthalate $\mathrm{H}_{2} \mathrm{~N}-\mathrm{UiO}-66 .{ }^{15}$ The $\mathrm{H}_{2} \mathrm{O}$ loading of $0.45 \mathrm{~g}$ $\mathrm{g}^{-1}$ correlates well to the micropore volume of $0.48 \mathrm{~cm}^{3} \mathrm{~g}^{-1}$ determined from $\mathrm{N}_{2}$ sorption experiments for a solvent of density $1 \mathrm{~g} \mathrm{~cm}^{-3}$, so that the micropores are filled at high $p / p_{0}$. This points to a high uniformity and hydrophilicity of the inner pore surface, without particularly hydrophobic sites. However, the conditions inside a thermally driven chiller can be considered to be isobaric rather than isothermal, due to the cyclic heating and cooling process. With the intent to simulate conditions close to reality, adsorption isobars were acquired at a partial water vapour pressure of $1.2 \mathrm{kPa}$ (corresponding to an evaporator temperature of $10^{\circ} \mathrm{C}$ ), while desorption was examined at $5.6 \mathrm{kPa}$ (corresponding to a condenser temperature of $35{ }^{\circ} \mathrm{C}$ ) (see Fig. 3). During adsorption, the main loading lift of $\mu \mathrm{p}-\mathrm{AF}$ occurs at $p / p_{0}<0.3$, permitting a medium temperature level of approx. $30^{\circ} \mathrm{C}$. The main desorption step occurs already between a relative pressure range of $0.4>p / p_{0}>0.25$, corresponding to a desorption ("driving") temperature of as low as $65{ }^{\circ} \mathrm{C}$ - a level which can be easily produced from solar or (surplus) district heat. These properties fit excellently to the demands typically anticipated for a thermally driven chiller. ${ }^{12,37}$ From in situ ad-/desorption PXRD analysis of $\mu$ p-AF (Fig. $2 d$ and S5 in ESI $\dagger$ ), we could find evidence that the structure is reversibly deformed during the transition. Based on the structural analogy between $\mu$ p-AF (Basolite ${ }^{\mathrm{TM}}$ A520) and MIL-53, the aluminium fumarate framework can also be assumed to be a flexible, 'breathing'-type network adapting to guest molecules, that is, it can assume different shapes and porosities depending on the guest's presence or absence. ${ }^{35,38}$ In the case of water as a guest molecule, however, the observed structural change in $\mu$ pAF was minor (see Fig. 2).

3.1.2 Differential heat of adsorption. The specific heat of adsorption $\Delta H_{\text {ads }}$ is a very important figure of merit especially for energy transformation applications. From a set of adsorption isotherms acquired at different temperatures, $\Delta H_{\text {ads }}$ can be calculated using a modified form of the Clausius-Clapeyron eqn (1): ${ }^{39}$

$$
\frac{\mathrm{d} p}{\mathrm{~d} T}=\frac{\Delta H_{\mathrm{ads}}}{T \cdot \Delta V_{\mathrm{ads}}}
$$

with the approximation that the vapour volume change upon adsorption, $\Delta V_{\text {ads }}$, can be expressed using the ideal gas law, integration of the formula yields eqn (2):

$$
\ln \frac{p}{p_{0}}=\frac{-\Delta H_{\mathrm{ads}}}{R \cdot T}+c
$$

The adsorption enthalpy for a specific amount of adsorbate can now be calculated from a dataset of different temperatures $T_{1}, T_{2}, \ldots, T_{n}$, required to obtain adsorption of this amount, and the corresponding absolute pressures $p_{1}, p_{2}, \ldots, p_{n}$, as the points $P_{n}\left(\ln \left(p_{n} / p_{0}\right) \mid 1 / T_{n}\right)$ will describe a straight line with the slope $-\Delta H_{\text {ads }} / R$. Values between isotherm data points were interpolated by straight lines, and $\Delta H_{\text {ads }}$ was calculated over the whole adsorption range (Fig. 4).

For the largest part of the adsorbed amount, the differential adsorption enthalpy $\Delta H_{\text {ads }}$ remains constantly about $10 \%$ above 


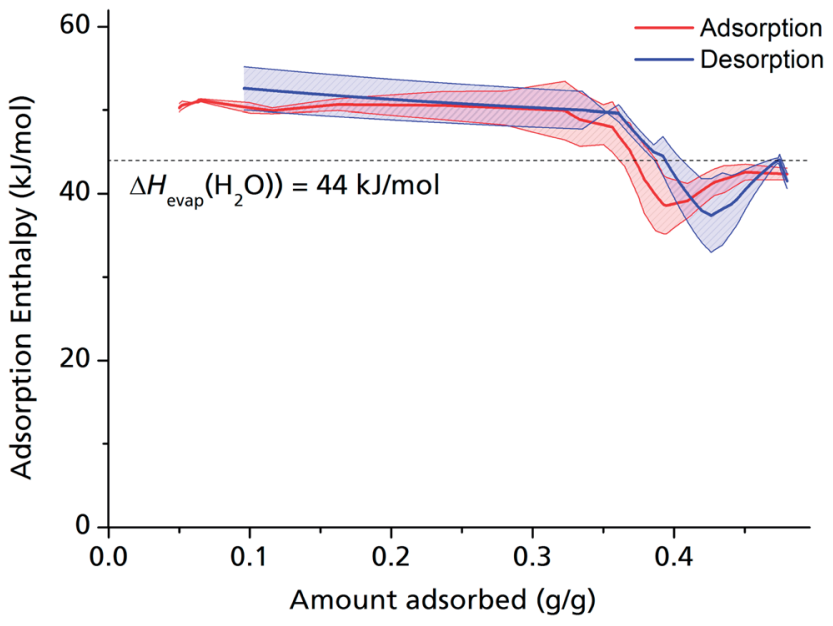

Fig. 4 Heat of adsorption for $\mu \mathrm{p}-\mathrm{AF}$-water, calculated from $298 \mathrm{~K}$, $313 \mathrm{~K}$ and $333 \mathrm{~K}$ isotherms. The shaded area indicates the standard deviation of the respective linear fits through the points $P_{1}, P_{2}, P_{3}$.

the evaporation enthalpy of water, which is a value in the range typically found for medium hydrophilic zeolites or silica gels. ${ }^{11,40}$ This points to a uniform, comparatively hydrophilic internal surface, with water molecules accumulating homogeneously along the channel walls. This behaviour differs considerably from that of, e.g., MIL-100 or MIL-101, where strong coordinative bonds are established between the first adsorbed $\mathrm{H}_{2} \mathrm{O}$ molecules and the highly polar, hydrophilic metal ion clusters, ${ }^{13}$ but makes sense given that $\mu \mathrm{P}-\mathrm{AF}$ does not contain metal ion clusters, but infinite $\mathrm{Al}-\mathrm{O}-\mathrm{Al}-\mathrm{O}$ chains running along the channel walls.

$\Delta H_{\text {ads }}$ drops substantially below the evaporation enthalpy of water when the pores are almost completely filled, which means that a simultaneous, endothermic process must take place at this point, such as the reversible deformation of the framework that can be deducted from the in situ PXRD measurements (Fig. 2). Another possible endothermic process, which may be responsible for the drop of adsorption enthalpy at high adsorbed amounts, which is not easy to detect, is the rearrangement of already adsorbed water molecules towards a closer, yet energetically less favourable configuration upon pore filling.

3.1.3 Heat capacity and conductivity. The heat capacity of dry bulk $\mu$ p-AF is between $1.05 \mathrm{~J} \mathrm{~g}^{-1} \mathrm{~K}^{-1}$ and $1.35 \mathrm{~J} \mathrm{~g}^{-1} \mathrm{~K}^{-1}$ in the temperature range between $50{ }^{\circ} \mathrm{C}$ and $145^{\circ} \mathrm{C}$ (see Fig. S3 in $\mathrm{ESI} \dagger)$. These values are in accordance with those measured for other MOFs, where heat capacities range from $0.8 \mathrm{~J} \mathrm{~g}^{-1} \mathrm{~K}^{-1}$ to $1.2 \mathrm{~J} \mathrm{~g}^{-1} \mathrm{~K}^{-1} \cdot{ }^{41}$

For the pressed pellet, the thermal conductivity in this temperature range lies around $0.12 \mathrm{~W} \mathrm{~m}^{-1} \mathrm{~K}^{-1}$.

3.1.4 Multicycle water sorption stability test. A metalorganic framework compound is often called "water-stable" when the powder can be recovered from water or from waterDMF mixtures without structural change as proven by powder X-ray diffraction. ${ }^{5,22,42}$ In the cyclic operational mode of sorption heat transformation appliances, the sorption material is subjected to numerous ad-/desorption cycles with simultaneous cyclic thermal stress. Under these conditions, hydrothermal stability is a crucial aspect and, therefore, has to be investigated separately via multi-cycle ad-/desorption experiments. Under the cycling conditions heat transfer to and from the sample is limited. The thermodynamic water sorption equilibrium is not completely reached within the individual cycles. Consequently, a $20 \mathrm{~h}$ thermodynamic analysis cycle was run before the cycling experiment and after every 20 cycles the equilibrium $\mathrm{H}_{2} \mathrm{O}$ uptake capacity of the material was determined.

Judged from the longer analysis cycles during the multi-cycle ad-/desorption experiments in Fig. 5, the adsorption capacity remains within the range to be expected from the volumetric measurements: $0.37 \mathrm{~g} \mathrm{~g}^{-1}$ after $20,0.38 \mathrm{~g} \mathrm{~g}^{-1}$ after $40,0.37 \mathrm{~g} \mathrm{~g}^{-1}$ after 60 and $0.37 \mathrm{~g} \mathrm{~g}^{-1}$ after 80 cycles. While the framework seems to lose approx. $6 \%$ of its weight during the first 20 cycles, this seems to have no impact on the sorption capacity itself. The decrease in dry mass indicates a further activation effect due to water sorption cycles. This post-activation phenomenon can be explained by stepwise removing of fumaric acid, which apparently could not be fully cleaved from the narrow and highly polar channels of $\mu \mathrm{p}-\mathrm{AF}$ by the initial washing procedure. During cycling however, the desorbing water vapour is likely to entrain the high-boiling, yet poorly water-soluble fumaric acid in a way similar to steam distillation.
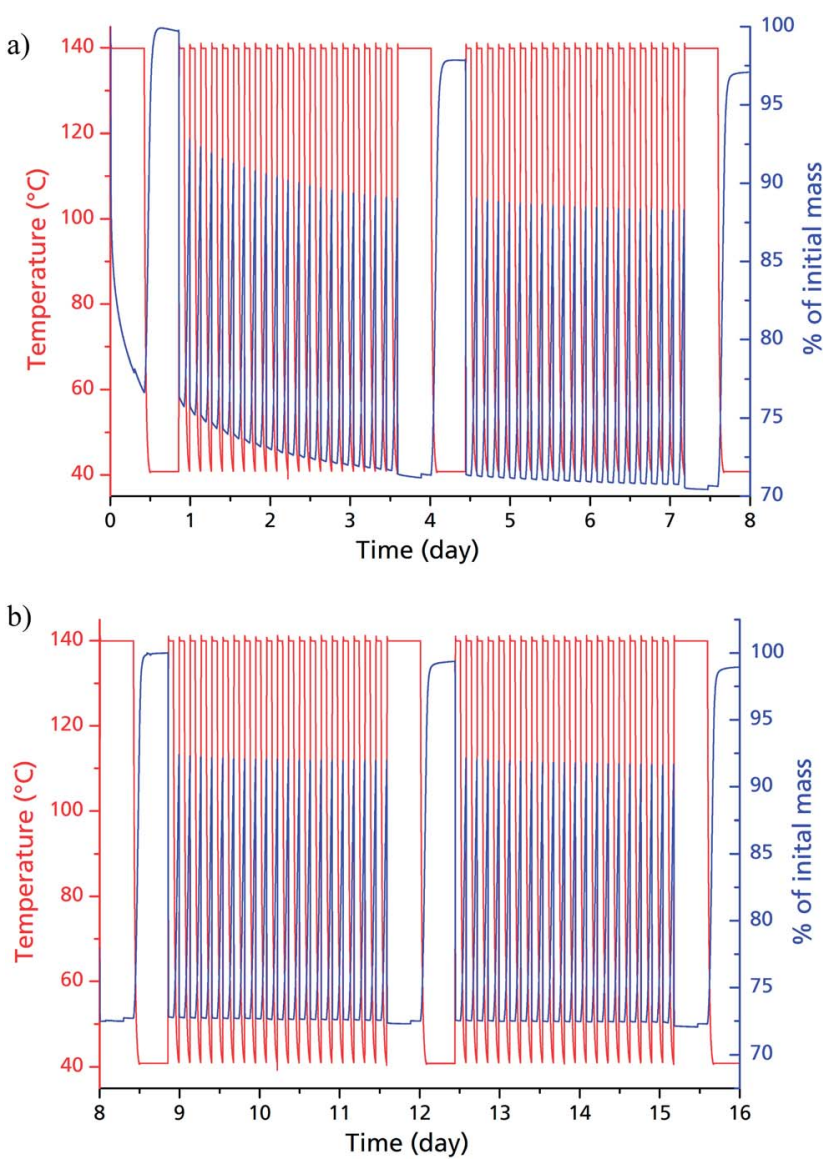

Fig. 5 Thermogravimetric adsorption/desorption cycling experiments for 40 cycles (a), and another 40 cycles (b) of bulk $\mu$ p-AF. Long segments at the beginning, in the middle and at the end of each experiment were conducted to determine the equilibrium loading of the sample. 


\section{$3.2 \mu$ p-AF@Al coating}

3.2.1 Coating synthesis. When performing thermal gradient synthesis, the temperature of the solution of aluminium nitrate and fumaric acid is maintained at $30{ }^{\circ} \mathrm{C}$ by active chilling, only the substrate itself is heated. Due to the arising temperature gradient, the MOF crystals form a layer covering only the very surface, with a growth rate of approx. 100 $\mu \mathrm{m} \mathrm{h}^{-1}$. Simply applying the original procedure for thermal gradient synthesis ${ }^{17}$ to $\mu \mathrm{p}-\mathrm{AF}$ did not yield the desired result. We found that several parameters had to be changed in order to obtain a sufficiently thick coating in a reasonable amount of time.

Replacement of the $\mathrm{Al}^{3+}$-source. As chloride anions are known to provoke corrosion of the most common metallic substrates, e.g., copper, aluminium, and also stainless steel alloys, the aluminium chloride used in the original synthesis procedure ${ }^{31}$ was replaced by an equimolar amount of aluminium nitrate nonahydrate.

Increase of reactant concentration. In order to speed up layer growth and obtain sufficiently thick layers, we doubled the concentrations of reactants (aluminium nitrate nonahydrate and fumaric acid) for a second run, compared to the original procedure.

Protective lacquer. For increased mechanical stability, one sample was additionally furnished with a protective lacquer. An industry-standard, highly water vapour permeable siliconeresin varnish was chosen for this purpose (Evonik Silikophen ${ }^{\circledR}$ P50/300).

Reaction temperature. We found that it was necessary to set the temperature of the substrate to $145{ }^{\circ} \mathrm{C}$ compared to $130{ }^{\circ} \mathrm{C}$ for the batch synthesis in order to obtain an evenly distributed coating. The temperature of the cooling jacket was set to $30^{\circ} \mathrm{C}$.

Under the conditions given above, a uniform coating of $\mu \mathrm{p}$ AF could be deposited on pretreated aluminium sheets (Fig. 6 and 7). As can be seen from the polished cross-section (see Fig. 7d), the coating consists of a macroporous and structured top layer with a thickness of approx. $280 \mu \mathrm{m}$ (top-down view in

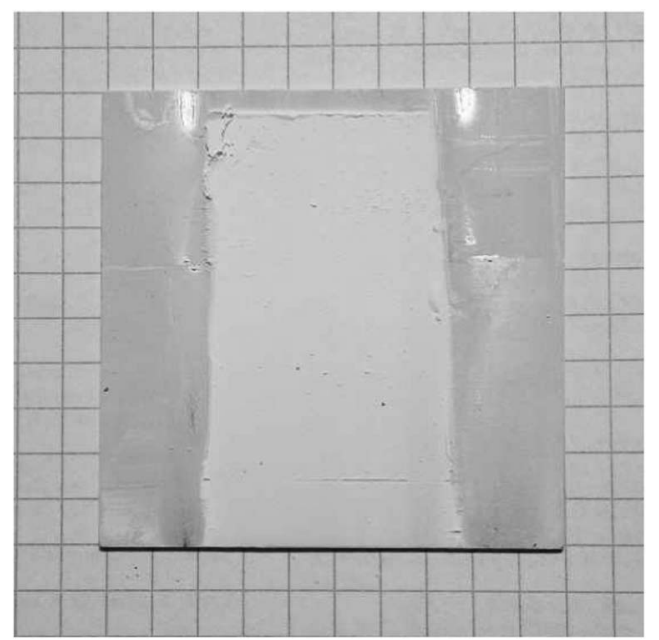

Fig. 6 Representative image of an $\mu$ p-AF@Al coated aluminium sheet Edges were covered by mounting clamps during coating synthesis.
Fig. 7b). Applying moderate force, the top layer can be removed with a spatula, exposing a denser and firmly adhering bottom layer with a thickness of only $20 \mu \mathrm{m}$ (Fig. 7c). Both layers consist of crystalline $\mu \mathrm{p}-\mathrm{AF}$, as proven by PXRD (see Fig. S6 in ESI $\dagger$ ).

The gravimetric density of the $\mu \mathrm{p}-\mathrm{AF}$ coating (determined by measuring and weighing a flake removed from the substrate) is $\rho_{\text {coating }}=0.61 \mathrm{~g} \mathrm{~cm}^{-3}$.

3.2.2 Crystal structure and multicycle stability of $\mu \mathrm{p}-\mathrm{AF}$ coating. From comparison of PXRD measurements of both sheet 1 and 2 (Fig. 8) with the PXRD for bulk $\mu$ p-AF (Fig. 2 and S2 in $\mathrm{ESI} \dagger$ ), it can be seen that the single crystalline phase within the coating can be ascribed to $\mu \mathrm{p}-\mathrm{AF} .^{34}$ The main peak at $2 \theta=$ $10.5^{\circ}$, however, is comparatively more intense, which suggests that a preferred orientation of crystallites is present. Such a behavior is well-known for polycrystalline layers, and can be
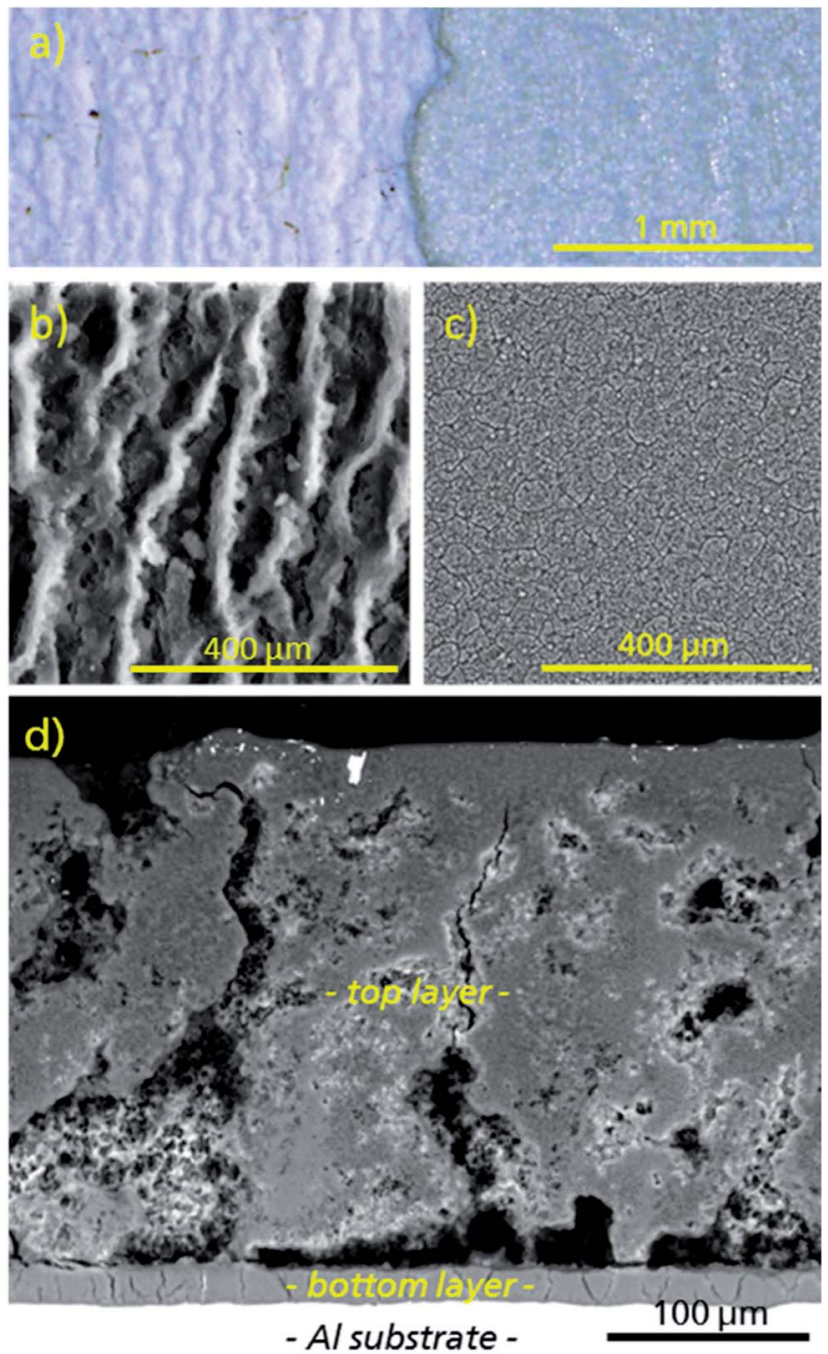

Fig. 7 (a) Representative optical microscope image of the $\mu$ p-AFaAl coating in top-down view, with the top layer being removed in the right part of the image in order to expose the bottom layer. The different structures can be seen in (b) (SEM image of the top-down view of the top layer) and (c) (SEM image of the top-down view of the bottom layer), and in the polished cross-section of the whole coating (d). 


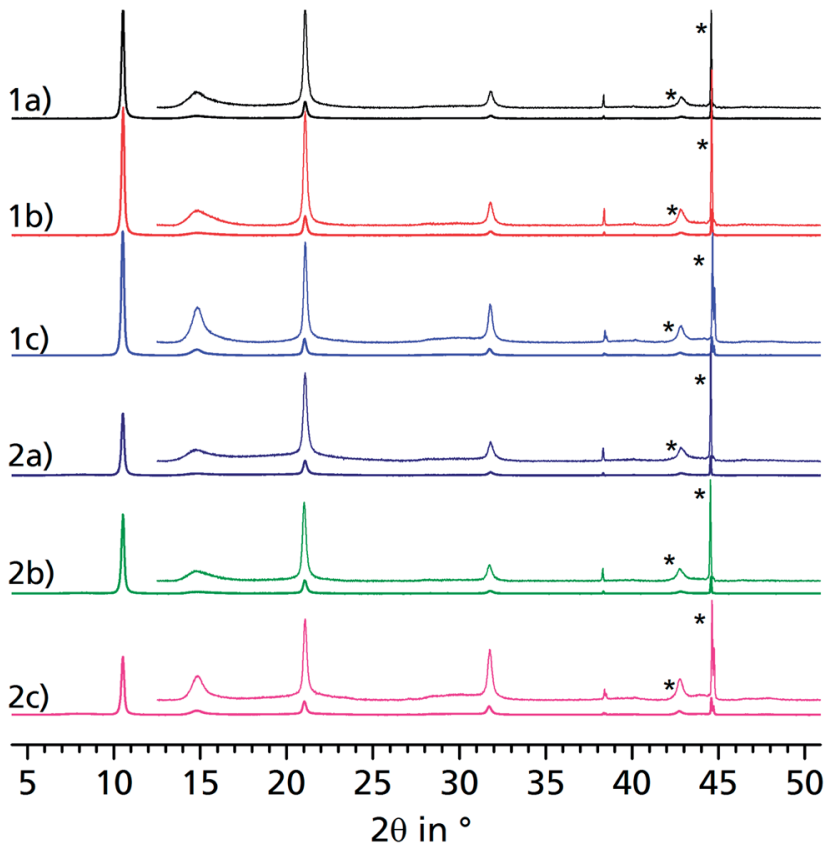

Fig. 8 PXRD of two representative $\mu$ p-AF@Al sheets 1 and 2, each before cycling (a), after 1500 (b) and 4500 (c) ad-/desorption cycles with water vapour. Sheet 2 has been covered with the silicon resin. Insets are multiplied by the factor of 6 for better visualization. Peaks marked with an asterisk ( $\star$ ) are caused by the Al substrate.

explained by evolutionary selection (van-der-Drift growth). ${ }^{43}$ Compared to sheet 1 , reflections of sheet 2 are less intense, because the sample was varnished with silicon resin.

When comparing the diffractograms of the coated sheets before cycling, after 1500 and after 4500 cycles, no weakening or broadening of the reflections can be seen in both cases. In fact, the intensity and sharpness of the reflections at $2 \theta=14.9^{\circ}$ and $31.8^{\circ}$ increases. This can be explained by recrystallization/ rearrangement phenomena during cycling, and also by a postactivation procedure as described above for bulk $\mu \mathrm{p}-\mathrm{AF}$.

After 1500 and 4500 cycles, the desorption isobar for the $\mu \mathrm{p}$ AF coating in Fig. 9 corresponds well to the isobar acquired for bulk $\mu$ p-AF (Fig. 3). Also, the $\mathrm{H}_{2} \mathrm{O}$ capacity of $0.37 \mathrm{~g} \mathrm{~g}^{-1}$ from the desorption isobar corresponds to the equilibrium loading in the multi-cycle experiments of bulk $\mu$ p-AF (Fig. 5). This is an excellent water uptake value as to the best of our knowledge, so far, no other MOF has shown such a stability towards the first $4500 \mathrm{ad} / \mathrm{des}$ orption cycles with water vapor ( $c f$. Fig. 8).

Sheet 2 was additionally covered with silicone resin and features the same shape of the isotherm after 4500 cycles, but with a smaller relative load, due to the additional weight added to the coating by the silicone resin (see Fig. S7 in ESI†).

3.2.3 Thermal conductivity and contact resistance of the coating. These two parameters directly determine the dissipation of the heat of adsorption. This correlates directly to the kinetics and hence to the performance of the finished adsorber. The conductivity of the $\mu \mathrm{p}-\mathrm{AF} @ \mathrm{Al}$ coating (Fig. 10) lies in a range of 0.33 to $0.31 \mathrm{~W} \mathrm{~m}^{-1} \mathrm{~K}^{-1}$, which is approx. 3 times higher than for the pressed pure Al-fumarate powder sample, despite its slightly lower density $\left(\rho_{\text {coating }}=0.61 \mathrm{~cm}^{3} \mathrm{~g}^{-1}, v s . \rho_{\text {pellet }}=0.71\right.$

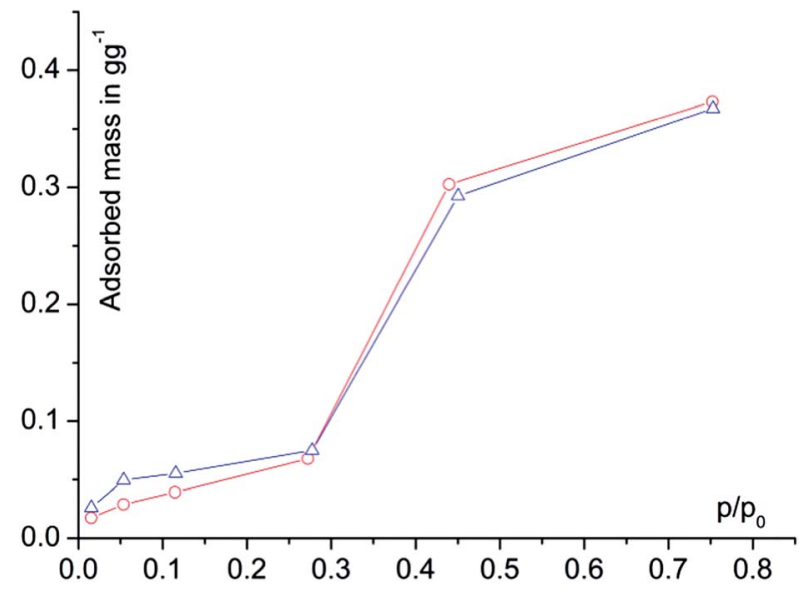

Fig. 9 Equilibrium water desorption isobars of a representative $\mu p$ AF@Al coating after 1500 ( $($ ) and 4500 cycles $(\triangle)$. Isobars were acquired gravimetrically under pure water vapour atmosphere, at $p_{\mathrm{H}_{2} \mathrm{O}}$ $=5.6 \mathrm{kPa}$, with $140{ }^{\circ} \mathrm{C} \geq T \geq 40^{\circ} \mathrm{C}$. Samples were degassed at $150^{\circ} \mathrm{C}$ under vacuum for $12 \mathrm{~h}$ prior to measurement, and loaded with water vapour for $8 \mathrm{~h}$. Adsorbed mass is based on the amount of $\mu \mathrm{p}-\mathrm{AF}$ coating.

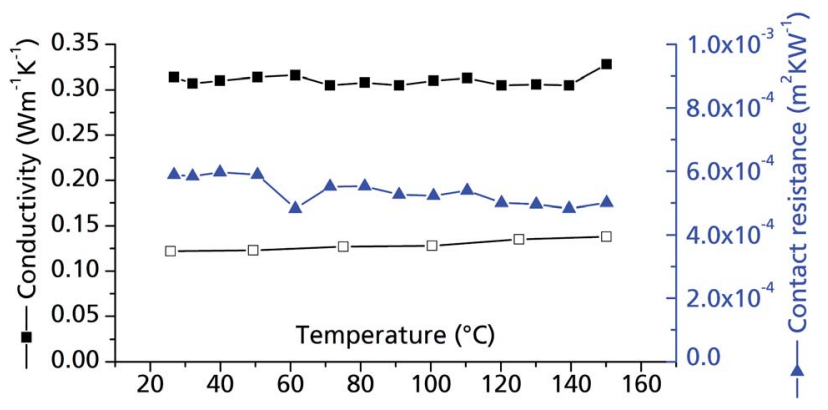

Fig. 10 Thermal conductivity of $\mu \mathrm{p}-\mathrm{AF}$. Measurements were conducted on bulk $\mu$ p-AF (pellet, $\varnothing=12.68 \mathrm{~mm}, h=1.71 \mathrm{~mm}$, forming pressure $=13 \mathrm{kN} ; \rho=0.714 \mathrm{~g} \mathrm{~cm}^{-3}$, empty symbols) and a $\mu \mathrm{p}-\mathrm{AF}$ (aAl coated sheet with protective layer (filled symbols). For the $c_{p}$ values, the curve determined for bulk $\mu \mathrm{p}-\mathrm{AF}$ was used in both cases (see Fig. S3 in ESI †).

$\mathrm{cm}^{3} \mathrm{~g}^{-1}$ ). The high thermal conductivity of the layer can be explained with the high uniformity of the layer and the fact that crystallites seem to be highly intergrown ( $c f$. Fig. 7). For comparison, a packed zeolite $4 \AA$ bed features a thermal conductivity of $0.09 \mathrm{~W} \mathrm{~m}^{-1} \mathrm{~K}^{-1}$ when no additives are used, ${ }^{44}$ and a silica gel packing about $0.2 \mathrm{~W} \mathrm{~m}^{-1} \mathrm{~K}^{-1} .^{45}$ An activated carbon bed has a conductivity of 0.15 to $0.5 \mathrm{~W} \mathrm{~m}^{-1} \mathrm{~K}^{-1} \cdot{ }^{46} \mathrm{On}$ the other hand, the conductivity of monocrystalline MOF-5 has even been reported as low as $0.35 \mathrm{~W} \mathrm{~m}^{-1} \mathrm{~K}^{-1}$. $^{47}$ The comparatively high thermal conductivity for the $\mu \mathrm{p}-\mathrm{AF} @ A \mathrm{Al}$ coating can be traced to the highly intergrown crystals within the coated sample (Fig. 7), so that intercrystalline heat transport is facilitated.

The contact resistance between the MOF layer and the resin coating is about $5.1 \times 10^{-4} \mathrm{~m}^{2} \mathrm{~K} \mathrm{~W}^{-1}$ in the examined temperature range (Fig. 10). For comparison, this value equals 
the contact resistance between a similar combination of materials (activated carbon pressed to an aluminium bronze surface, but with a pressure of $1.0 \mathrm{MPa}$ ) and is hence a very acceptable value for a MOF-metal interface. ${ }^{48}$

\section{Conclusions}

The thorough investigation of the water sorption properties of $\mu \mathrm{p}-\mathrm{AF}$ show that this remarkable MOF may be employed as a promising adsorbent for heat transformation applications. The maximum water exchange of $0.35 \mathrm{~g} \mathrm{~g}^{-1}$ is certainly lower than in other MOFs such as UiO-66 (ref. 15) or MIL-100, ${ }^{13}$ but it can be fully utilized under realistic, isobaric working conditions due to the hydrophilicity of $\mu \mathrm{p}-\mathrm{AF}$. The characteristic, steep s-shape of the isotherm in a relative pressure band of $0.2<p / p_{0}<0.35$ has not been observed for other water-stable MOFs before. In this context, $\mu \mathrm{p}-\mathrm{AF}$ can be compared best to modern, hydrophilic, zeotype adsorbents such as AlPO-18 or AlPO- $4 .^{40}$ In terms of cyclic hydrothermal stability, $\mu$ p-AF surpasses other hydrophilic MOFs, even other aluminium carboxylates such as MIL100(Al). ${ }^{13}$

$\mu \mathrm{p}-\mathrm{AF}$ can already be produced comparatively cost-efficiently via a simple precipitation reaction. This is in contrast to, e.g., the template-based AlPO-18 synthesis, or various hydro-/solvothermal synthesis routes required for other MOFs. $\mu \mathrm{p}-\mathrm{AF}$ is also free of harmful components such as heavy metals or critical organic compounds. Aluminium salts are approved as EU food additives (E520-523), as well as several fumarates (E365-368).

The way towards the application has been cleared further by the successful preparation of a thick, thermally well coupled $\mu \mathrm{p}$ AF coating on a metallic substrate via the thermal gradient approach, and its hydrothermal stability proven for 4500 ad-/ desorption cycles, renders this material very interesting also for other applications such as catalysis or gas storage.

The chemically versatile $\mathrm{C}=\mathrm{C}$-bond of the fumarate linker can be a valuable anchor for further tailoring of $\mu \mathrm{p}-\mathrm{AF}$ by postsynthetic modifications (for example, it might serve as a complex ligand after hydroxylation, or directly via the $\pi$-bond electrons). This topic should be investigated in the future, in order to render $\mu \mathrm{p}-\mathrm{AF}$ more versatile also for highly specific applications.

\section{Acknowledgements}

Funding by the Federal German Ministry of Economics (BMWi) under grant-\# 0327851A/B, and by the Fraunhofer Society under grant-\# MAVO 824704 is gratefully acknowledged. Part of this project is also funded by DFG grant Ja466/25-1 to CJ. This work is dedicated to Prof. Christel Marian on the occasion of her 60th birthday.

\section{Notes and references}

1 J. R. Long and O. M. Yaghi, Chem. Soc. Rev., 2009, 38, 12131214; M. O'Keeffe and O. M. Yaghi, Chem. Rev., 2012, 112, 675-702; C. Janiak and J. K. Vieth, New J. Chem., 2010, 34, 2366-2388.
2 R. J. Kuppler, D. J. Timmons, Q.-R. Fang, J.-R. Li, T. A. Makal, M. D. Young, D. Yuan, D. Zhao, W. Zhuang and H.-C. Zhou, Coord. Chem. Rev., 2009, 253, 3042-3066; M. P. Suh, H. J. Park, T. K. Prasad and D. W. Lim, Chem. Rev., 2012, 112, 782-835; H. Wu, Q. Gong, D. H. Olson and J. Li, Chem. Rev., 2012, 112, 836-868; L. J. Murray, M. Dincă and J. R. Long, Chem. Soc. Rev., 2009, 38, 1294-1314.

3 J. A. Mason, M. Veenstra and J. R. Long, Chem. Sci., 2014, 5, 32-51; R. Sathre and E. Masanet, RSC Adv., 2013, 3, 49644975; J. Liu, P. K. Thallapally, B. P. McGrail, D. R. Bown and J. Liu, Chem. Soc. Rev., 2012, 41, 2308-2322; H. Amrouche, B. Creton, F. Siperstein and C. Nieto-Draghi, RSC Adv., 2012, 2, 6028-6035.

4 J. R. Li, J. Sculley and H. C. Zhou, Chem. Rev., 2012, 112, 869932; Z. Zhang, Y. Zhao, Q. Gong, Z. Li and J. Li, Chem. Commun., 2013, 49, 653-661; H. B. Tanh Jeazet, C. Staudt and C. Janiak, Dalton Trans., 2012, 41, 14003-14027; X. Y. Chen, V.-T. Hoang, D. Rodrigue and S. Kaliaguine, RSC Adv., 2013, 3, 24266-24279; G. Férey, C. Serre, T. Devic, G. Maurin, H. Jobic, P. L. Llewellyn, G. De Weireld, A. Vimont, M. Daturi and J. S. Chang, Chem. Soc. Rev., 2011, 40, 550-562; J.-R. Li, Y. Ma, M. C. McCarthy, J. Sculley, J. Yu, H.-K. Jeong, P. B. Balbuena and H.-C. Zhou, Coord. Chem. Rev., 2011, 255, 1791-1823; N. Hara, M. Yoshimune, H. Negishi, K. Haraya, S. Hara and T. Yamaguchi, RSC Adv., 2013, 3, 14233-14236; J. H. Yoon, D. Kim, X. Song, S. Han, J. Shin, S. B. Hong and M. Soo Lah, RSC Adv., 2012, 2, 11566-11573; M. Fischer, F. Hoffmann and M. Fröba, $R S C A d v$., 2012, 2, 4382-4396; L. Ge, A. Du, M. Hou, V. Rudolph and Z. Zhu, RSC Adv., 2012, 2, 11793-11800.

5 K. A. Cychosz and A. J. Matzger, Langmuir, 2010, 26, 1719817202; Y.-X. Tan, Y.-P. He, M. Wang and J. Zhang, RSC Adv., 2014, 4, 1480-1483.

6 P. Horcajada, R. Gref, T. Baati, P. K. Allan, G. Maurin, P. Couvreur, G. Férey, R. E. Morris and C. Serre, Chem. Rev., 2012, 112, 1232-1268.

7 J. Lee, O. K. Farha, J. Roberts, K. A. Scheidt, S. T. Nguyen and J. T. Hupp, Chem. Soc. Rev., 2009, 38, 1450-1459; M. Yoon, R. Srirambalaji and K. Kim, Chem. Rev., 2012, 112, 11961231; M. A. Gotthardt, A. Beilmann, R. Schoch, J. Engelke and W. Kleist, RSC Adv., 2013, 3, 10676-10679; Y. Fu, D. Sun, M. Qin, R. Huang and Z. Li, RSC Adv., 2012, 2, 3309-3314.

8 A. U. Czaja, N. Trukhan and U. Muller, Chem. Soc. Rev., 2009, 38, 1284-1293; G. Férey, Dalton Trans., 2009, 4400-4415; M. J. Prakash and M. S. Lah, Chem. Commun., 2009, 33263341; C. Hou, Q. Xu, Y. Wang and X. Hu, RSC Adv., 2013, 3, 19820-19823; J. F. Guo, C. M. Li, X. L. Hu, C. Z. Huang and Y. F. Li, $R S C A d v$., 2014, 4, 9379-9382.

9 F. Jeremias, D. Fröhlich, C. Janiak and S. K. Henninger, New J. Chem., 2014, 38, 1846-1852; C. Janiak and S. K. Henninger, Nachr. Chem., 2013, 61, 520-523.

10 Y. I. Aristov, Appl. Therm. Eng., 2013, 50, 1610-1618; R. Wang and R. Oliveira, Prog. Energy Combust. Sci., 2006, 32, 424-458; Y. I. Aristov, Int. J. Refrig., 2009, 32, 675-686; L. G. Gordeeva, A. Freni, Y. I. Aristov and G. Restuccia, Ind. Eng. Chem. Res., 
2009, 48, 6197-6202; Y. I. Aristov, J. Chem. Eng. Jpn., 2007, 40, 1242-1251; Y. I. Aristov, M. M. Tokarev, A. Freni, I. S. Glaznev and G. Restuccia, Microporous Mesoporous Mater., 2006, 96, 65-71; Y. I. Aristov, B. Dawoud, I. S. Glaznev and A. Elyas, Int. J. Heat Mass Transfer, 2008, 51, 4966-4972; Y. I. Aristov, G. Restuccia, G. Cacciola and V. N. Parmon, Appl. Therm. Eng., 2002, 22, 191-204.

11 N. C. Srivastava and I. W. Eames, Appl. Therm. Eng., 1998, 18, 707-714.

12 S. K. Henninger, F. Jeremias, H. Kummer and C. Janiak, Eur. J. Inorg. Chem., 2012, 2625-2634.

13 F. Jeremias, A. Khutia, S. K. Henninger and C. Janiak, J. Mater. Chem., 2012, 22, 10148-10151.

14 J. Ehrenmann, S. K. Henninger and C. Janiak, Eur. J. Inorg. Chem., 2011, 471-474.

15 F. Jeremias, V. Lozan, S. Henninger and C. Janiak, Dalton Trans., 2013, 42, 15967-15973.

16 S. K. Henninger, H. A. Habib and C. Janiak, J. Am. Chem. Soc., 2009, 131, 2776-2777.

17 F. Jeremias, S. K. Henninger and C. Janiak, Chem. Commun., 2012, 48, 9708-9710.

18 A. Rezk, R. Al-Dadah, S. Mahmoud and A. Elsayed, Int. J. Heat Mass Transfer, 2012, 55, 7366-7374.

19 A. Khutia, H. U. Rammelberg, T. Schmidt, S. Henninger and C. Janiak, Chem. Mater., 2013, 25, 790-798; H. Jasuja, J. Zang, D. S. Sholl and K. S. Walton, J. Phys. Chem. C, 2012, 116, 23526-23532; S. M. Cohen, Chem. Rev., 2012, 112, 9701000; G. Akiyama, R. Matsuda, H. Sato, A. Hori, M. Takata and S. Kitagawa, Microporous Mesoporous Mater., 2012, 157, 89-93.

20 P. Küsgens, M. Rose, I. Senkovska, H. Fröde, A. Henschel, S. Siegle and S. Kaskel, Microporous Mesoporous Mater., 2009, 120, 325-330.

21 M. Taddei, A. Ienco, F. Costantino and A. Guern, RSC Adv., 2013, 3, 26177-26183; J. J. Low, A. I. Benin, P. Jakubczak, J. F. Abrahamian, S. A. Faheem and R. R. Willis, J. Am. Chem. Soc., 2009, 131, 15834-15842.

22 K. S. Park, Z. Ni, A. P. Cote, J. Y. Choi, R. Huang, F. J. UribeRomo, H. K. Chae, M. O'Keeffe and O. M. Yaghi, Proc. Natl. Acad. Sci. U. S. A., 2006, 103, 10186-10191.

23 A. Demessence, D. M. D'Alessandro, M. L. Foo and J. R. Long, J. Am. Chem. Soc., 2009, 131, 8784-8786.

24 J. H. Cavka, S. Jakobsen, U. Olsbye, N. Guillou, C. Lamberti, S. Bordiga and K. P. Lillerud, J. Am. Chem. Soc., 2008, 130, 13850-13851; C. Gomes Silva, I. Luz, F. X. Llabres i Xamena, A. Corma and H. Garcia, Chem.-Eur. J., 2010, 16, 11133-11138; D. Feng, Z.-Y. Gu, J.-R. Li, H.-L. Jiang, Z. Wei and H.-C. Zhou, Angew. Chem., 2012, 124, 10453-10456.

25 J. M. Taylor, R. K. Mah, I. L. Moudrakovski, C. I. Ratcliffe, R. Vaidhyanathan and G. K. Shimizu, J. Am. Chem. Soc., 2010, 132, 14055-14057; C. Serre, N. Stock, T. Bein and G. Férey, Inorg. Chem., 2004, 43, 3159-3163.

26 V. Colombo, C. Montoro, A. Maspero, G. Palmisano, N. Masciocchi, S. Galli, E. Barea and J. A. Navarro, J. Am. Chem. Soc., 2012, 134, 12830-12843.

27 J. Liu, F. Sun, F. Zhang, Z. Wang, R. Zhang, C. Wang and S. Qiu, J. Mater. Chem., 2011, 21, 3775; S. Kayaert, S. Bajpe,
K. Masschaele, E. Breynaert, C. E. A. Kirschhock and J. A. Martens, Thin Solid Films, 2011, 519, 5437-5440; P. Falcaro, A. J. Hill, K. M. Nairn, J. Jasieniak, J. I. Mardel, T. J. Bastow, S. C. Mayo, M. Gimona, D. Gomez, H. J. Whitfield, R. Ricco, A. Patelli, B. Marmiroli, H. Amenitsch, T. Colson, L. Villanova and D. Buso, Nat. Commun., 2011, 2, 237; A. Schoedel, C. Scherb and T. Bein, Angew. Chem., Int. Ed., 2010, 49, 7225-7228; V. V. Guerrero, Y. Yoo, M. C. McCarthy and H.-K. Jeong, J. Mater. Chem., 2010, 20, 3938; A. Centrone, Y. Yang, S. Speakman, L. Bromberg, G. C. Rutledge and T. A. Hatton, J. Am. Chem. Soc., 2010, 132, 15687-15691; H. Guo, G. Zhu, I. J. Hewitt and S. Qiu, J. Am. Chem. Soc., 2009, 131, 1646-1647; J. Gascon, S. Aguado and F. Kapteijn, Microporous Mesoporous Mater., 2008, 113, 132-138.

28 N. Campagnol, T. Van Assche, T. Boudewijns, J. Denayer, K. Binnemans, D. De Vos and J. Fransaer, J. Mater. Chem. A, 2013, 1, 5827; T. R. C. Van Assche, G. Desmet, R. Ameloot, D. E. De Vos, H. Terryn and J. F. M. Denayer, Microporous Mesoporous Mater., 2012, 158, 209-213; S. A. Silkin, V. I. Petrenko and A. I. Dikusar, Surf. Eng. Appl. Electrochem., 2010, 46, 1-8; R. Ameloot, L. Pandey, M. Van der Auweraer, L. Alaerts, B. F. Sels and D. E. De Vos, Chem. Commun., 2010, 46, 3735-3737; R. Ameloot, E. Gobechiya, H. Uji-i, J. A. Martens, J. Hofkens, L. Alaerts, B. F. Sels and D. E. De Vos, Adv. Mater., 2010, 22, 2685-2688; R. Ameloot, L. Stappers, J. Fransaer, L. Alaerts, B. F. Sels and D. E. De Vos, Chem. Mater., 2009, 21, 2580-2582; A. Doménech, H. García, M. T. Doménech-Carbó and F. Llabrés-iXamena, Electrochem. Commun., 2006, 8, 1830-1834.

29 Y. Yoo and H. K. Jeong, Chem. Commun., 2008, 2441-2443. 30 D. Zacher, O. Shekhah, C. Wöll and R. A. Fischer, Chem. Soc. Rev., 2009, 38, 1418-1429; C. Scherb, R. Koehn and T. Bein, J. Mater. Chem., 2010, 20, 3046.

31 C. Kiener, U. Müller and M. Schubert, Germany Pat. WO 2007/118841 A2, 2007.

32 C. Kiener, U. Müller and M. Schubert, US Pat. 12/297,666, 2012; E. Leung, U. Müller, N. Trukhan, H. Mattenheimer and G. Cox, US Pat. 13/249,943, 2012.

33 B. Yilmaz, N. Trukhan and U. Müller, Chin. J. Catal., 2012, 33, 3-10.

34 M. Gaab, N. Trukhan, S. Maurer, R. Gummaraju and U. Müller, Microporous Mesoporous Mater., 2012, 157, 131-136.

35 T. Loiseau, C. Serre, C. Huguenard, G. Fink, F. Taulelle, M. Henry, T. Bataille and G. Férey, Chem.-Eur. J., 2004, 10, 1373-1382; C. Serre, F. Millange, C. Thouvenot, M. Noguès, G. Marsolier, D. Louër and G. Férey, J.Am. Chem. Soc., 2002, 124, 13519-13526.

36 G. Langer, J. Hartmann and M. Reichling, Rev. Sci. Instrum., 1997, 68, 1510.

37 Y. I. Aristov, Appl. Therm. Eng., 2012, 42, 18-24; B. B. Saha, A. Chakraborty, S. Koyama, K. Srinivasan, K. C. Ng, T. Kashiwagi and P. Dutta, Appl. Phys. Lett., 2007, 91, 111902.

38 J. Liu, F. Zhang, X. Zou, G. Yu, N. Zhao, S. Fan and G. Zhu, Chem. Commun., 2013, 49, 7430-7432.

39 J. Rouquerol, F. Rouquerol and K. S. W. Sing, Adsorption by Powders and Porous Solids, Academic Press, San Diego, 1998. 
40 S. K. Henninger, F. P. Schmidt and H. M. Henning, Appl. Therm. Eng., 2010, 30, 1692-1702.

41 B. Mu and K. S. Walton, J. Phys. Chem. C, 2011, 115, 2274822754.

42 M. Kandiah, M. H. Nilsen, S. Usseglio, S. Jakobsen, U. Olsbye, M. Tilset, C. Larabi, E. A. Quadrelli, F. Bonino and K. P. Lillerud, Chem. Mater., 2010, 22, 6632-6640; V. Guillerm, F. Ragon, M. Dan-Hardi, T. Devic, M. Vishnuvarthan, B. Campo, A. Vimont, G. Clet, Q. Yang, G. Maurin, G. Férey, A. Vittadini, S. Gross and C. Serre, Angew. Chem., Int. Ed., 2012, 51, 9267-9271.

43 A. Van der Drift, Philips Res. Rep., 1967, 22, 267.
44 L. Pino, Y. Aristov, G. Cacciola and G. Restuccia, Adsorption, 1997, 3, 33-40.

45 J. M. Gurgel and R. P. Klüppel, Chem. Eng. J. Biochem. Eng. J., 1996, 61, 133-138.

46 D. Menard, X. Py and N. Mazet, Chem. Eng. Process., 2007, 46, 565-572.

47 B. L. Huang, Z. Ni, A. Millward, A. J. H. McGaughey, C. Uher, M. Kaviany and O. Yaghi, Int. J. Heat Mass Transfer, 2007, 50, 405-411.

48 M. Khandelwal and M. M. Mench, J. Power Sources, 2006, 161, 1106-1115. 